\title{
PRELIMINARY ANALYSIS OF ACOUSTIC MEASUREMENTS FROM THE NASA-GULFSTREAM AIRFRAME NOISE FLIGHT TEST
}

\author{
Mehdi R. Khorrami, David P. Lockard ${ }^{\dagger}$, William M. Humphreys, Jr.**, Meelan M. Choudhari* \\ NASA Langley Research Center \\ MS 128, Hampton, VA \\ and \\ Thomas Van de Ven ${ }^{* * *}$ \\ Gulfstream Aerospace Corporation \\ Savannah, Georgia
}

\begin{abstract}
The NASA-Gulfstream joint Airframe Noise Flight Test program was conducted at the NASA Wallops Flight Facility during October, 2006. The primary objective of the AFN flight test was to acquire baseline airframe noise data on a regional jet class of transport in order to determine noise source strengths and distributions for model validation. To accomplish this task, two measuring systems were used: a ground-based microphone array and individual microphones. Acoustic data for a Gulfstream G550 aircraft were acquired over the course of ten days. Over twenty-four test conditions were flown. The test matrix was designed to provide an acoustic characterization of both the full aircraft and individual airframe components and included cruise to landing configurations. Noise sources were isolated by selectively deploying individual components (flaps, main landing gear, nose gear, spoilers, etc.) and altering the airspeed, glide path, and engine settings. The AFN flight test program confirmed that the airframe is a major contributor to the noise from regional jets during landing operations. Sound pressure levels from the individual microphones on the ground revealed the flap system to be the dominant airframe noise source for the G550 aircraft. The corresponding array beamform maps showed that most of the radiated sound from the flaps originates from the side edges. Using velocity to the sixth power and Strouhal scaling of the sound pressure spectra obtained at different speeds failed to collapse the data into a single spectrum. The best data collapse was obtained when the frequencies were left unscaled.
\end{abstract}

\section{Introduction}

Reduction and mitigation of community noise resulting from civil aircraft operations is an important goal of NASA's Aeronautics Research Mission Directorate. Airframe noise (AFN) is a key aircraft noise component during approach and landing. The ultimate goal of AFN research is to develop the enabling capabilities and technologies for enhanced prediction and reduction of aircraft noise. Advances in prediction methodologies for airframe noise require high-quality flight test data, supplemented by ground based model scale tests, to guide development and provide validation of prediction models.

Full-scale fly-over noise measurements in the US and Europe have been instrumental in identifying the predominant airframe noise sources for civil transports ${ }^{1-6}$ as well as help advance the development of phased microphone array design and post processing techniques ${ }^{6}$. Although expensive and intricate, full-scale tests provide the natural environment whereby installation, geometric fidelity, and Reynolds number effects on noise generation and radiation are addressed simultaneously. Understandably, the majority of past flight tests targeted large civil transports where complex high-lift and undercarriage systems produce dominant airframe noise sources. For instance, flight test investigations of noise abatement devices for Airbus A340 and Boeing 777 aircraft are reported in references 7 and 8, respectively.

Although air travel as a whole is expected to grow modestly during the next several years, the segment of the flights served by regional jets is forecast to experience strong growth. Yet, there is hardly any detailed flight test acoustic data

\footnotetext{
*Aerospace Technologist, Computational AeroSciences Branch, Associate Fellow AIAA

'Aerospace Technologist, Computational AeroSciences Branch, Senior Member AIAA

***Aerospace Technologist, Aeroacoustics Branch, Senior Member AIAA

*** Senior Acoustics Engineer, Acoustics \& Vibration Group, Member AIAA
} 
for this important class of aircraft. Fly-over airframe noise measurements for a Vickers VC 10 and a DC-9-31 were acquired by Fethney ${ }^{9}$ and Bauer and Munson ${ }^{10}$ more than thirty years ago. They provide the sound pressure level spectra for landing and several other configurations. However, source localization maps which are the hallmark of modern microphone array measurements are not available from these earlier studies. From an array validation study, limited beamform maps were reported for a regional jet by Michel et.al. ${ }^{1}$ Thus, there remains a need for conducting detailed airframe noise measurements of regional jet aircraft.

The primary objective of the AFN flight test was to acquire baseline airframe noise measurements on a regional jet class of transport using both a ground-based acoustic array and individual, certification quality microphones. The AFN flight test is one phase of a larger, NASA-Gulfstream effort aimed at collecting a high-fidelity aerodynamic and acoustic database in order to provide the necessary data for benchmarking noise prediction tools.

\section{Test Aircraft and Facility}

\section{$2.1 \quad$ Test Aircraft}

Gulfstream G550 and G450 aircraft were used as the test beds for the flight test. However, the main focus of the test was the G550. The main reason for this choice is the fairly large size of the G550 aircraft, which closely resembles a typical regional jet transport. In this paper we have restricted our discussions to the G550 plane and the corresponding acoustic measurements obtained for this aircraft. The description of the G450 aircraft and its acoustic footprint will be reported at a later date. The G550 has a "T" tail configuration, with twin engines aft-mounted to the fuselage of the aircraft. The aircraft outline is displayed in Fig.1 and the relevant dimensions are given in Table I.

\begin{tabular}{|l|c|c|}
\hline \multicolumn{3}{|c|}{ Table I. G550 Dimensions } \\
\hline Overall Length & $96.42 \mathrm{ft}$ & $29.39 \mathrm{~m}$ \\
\hline Height & $25.83 \mathrm{ft}$ & $7.87 \mathrm{~m}$ \\
\hline Wing Span & $93.5 \mathrm{ft}$ & $28.5 \mathrm{~m}$ \\
\hline Gross Wing Area & $1137 \mathrm{sq} \mathrm{ft}$ & $105.63 \mathrm{sq} \mathrm{m}$ \\
\hline MAC & $13.86 \mathrm{ft}$ & $4.22 \mathrm{~m}$ \\
\hline Flap Span/per side & $25.58 \mathrm{ft}$ & $7.8 \mathrm{~m}$ \\
\hline Flap Area/per side & $94.7 \mathrm{sq} \mathrm{ft}$ & $8.8 \mathrm{sq} \mathrm{m}$ \\
\hline Tail Plane Span & $35.17 \mathrm{ft}$ & $10.72 \mathrm{~m}$ \\
\hline Tail Plane Area & $244.86 \mathrm{sq} \mathrm{ft}$ & $22.75 \mathrm{sq} \mathrm{m}$ \\
\hline Max Gross Takeoff Weight & $91,000 \mathrm{lb}$ & $40,991 \mathrm{~kg}$ \\
\hline
\end{tabular}

\section{$2.2 \quad$ Facility}

The AFN test was executed over runway 4 at the NASA Wallops Flight Facility (WFF) on the Eastern Shore of Virginia. With a length of $8750 \mathrm{ft}(2667 \mathrm{~m})$ and a width of $150 \mathrm{ft}(45.7 \mathrm{~m})$, runway 4 is the longest of three runways available at the facility. Figure 2 shows the south-end aerial view of runway 4 . This runway was selected in order to meet several important criteria essential for the successful completion of the AFN test. The most critical elements under consideration were: a) the availability of a large flat overrun section with adjacent grassy fields, where the NASA microphone array and Gulfstream free field microphones could be placed next to each other along the aircraft approach direction; b) the presence of a long runway to minimize potential risks during low-altitude, low-speed fly-over at low engine power settings; and c) the maximum distance between the installed microphones and the local roads in order to reduce the impact of background noise created by traffic. 


\section{Test Procedure and Test Conditions}

\section{$3.1 \quad$ Test Procedure}

The AFN test was performed with the aircraft flying a "racetrack" pattern, simulating the approach path to landing as it passed over the measurement location. The actual glide slope, angle of attack, and other flight parameters were recorded, but are too extensive to be included in this paper. The majority of the test conditions were executed with the engines at an approach-idle setting in order to minimize the contamination of airframe noise measurements from the engine. The target altitude as the aircraft passed over the microphones was 400 feet $(120 \mathrm{~m})$, with allowed deviations of $\pm 50 \mathrm{ft}(15.2 \mathrm{~m})$ in the vertical height and $\pm 75 \mathrm{ft}(22.9 \mathrm{~m})$ in the lateral distance. On several occasions however, due to unusual atmospheric conditions at heights near $400 \mathrm{ft}(120 \mathrm{~m})$, the target altitude was lowered to $350 \mathrm{ft}(106.7 \mathrm{~m})$ with a more stringent allowed vertical deviation of $\pm 25 \mathrm{ft}(7.6 \mathrm{~m})$. The height of the test airplane $(\mathrm{Z})$, lateral deviation $(\mathrm{Y})$, and down range position (X) relative to each microphone was determined by a differential Global Positioning System (GPS) comprised of two GPS receivers. One GPS receiver was placed at a surveyed position on the top of the research tower at WFF, while the other receiver was placed onboard the aircraft. The recordings of GPS position and GPS time were compared and GPS errors removed to give a time history of the aircraft position to sub-meter accuracy.

An automated data acquisition system called the Gulfstream Instrumentation Flight Test System or "GIFTS" was used to acquire airplane and engine performance parameters during each flyover. The system recorded the following parameters as a function of time:

$\begin{array}{llcl}\text { 1) } & \text { Event marks } & 6) & \text { Pitch Attitude } \\ \text { 2) } & \text { Radar altitude } & 7) & \text { Engine Pressure Ratio } \\ 3) & \text { Pressure altitude } & 8) & \text { Low pressure compressor speed } \\ 4) & \text { Indicated airspeed } & 9) & \text { High pressure compressor speed } \\ \text { 5) } & \text { Static air temperature } & \text { 10) } & \text { Engine surge bleed position } \\ & & 11) & \text { Aircraft Position (DGPS) }\end{array}$

Time synchronization of these parameters with the acoustic data was established by transmitting an event mark (tone) on board the aircraft.

Local meteorological conditions were recorded approximately every hour using a weather balloon and once a minute using a ground station. The ground weather station, located at the NASA acoustic array data van, was positioned on top of a $25-\mathrm{ft}(7.6 \mathrm{~m})$ mast. Both the data van and the balloon launch location were within several hundred meters of the microphone array position. Given the target altitude for the aircraft flyover and in order to limit loss of test time, balloon ascents were mostly restricted to a height of $500 \mathrm{ft}(152.5 \mathrm{~m})$. During a typical test-day operation, the weather balloon was released to a height of $25 \mathrm{ft}(7.6 \mathrm{~m})$ and then held at that height for several seconds while a quick comparison of the balloon readings with those from the ground station was conducted. In nearly all instances, the differences between the two readings were within the anticipated error bounds and thus, the balloon was allowed to continue its normal ascent. As a measure of variability in the recorded data, wind velocity, temperature, and relative humidity were measured both on the ascent and descent of the balloon. Based on findings from pre-test trial launches, the balloon ascent and descent rates were typically restricted below $2 \mathrm{ft} / \mathrm{s}(0.6 \mathrm{~m} / \mathrm{s})$ in order to minimize the errors in measured atmospheric profiles. The measured data were transmitted to the ground and immediately displayed on a laptop computer for quick analysis to enable relevant decisions regarding flight operations. A sample plot of temperature vs. relative humidity, along with the profiles of other measured quantities, is shown in Fig.3. In the temperature/relative humidity plot, the region inside the red outline corresponds to absorption of less than $11 \mathrm{~dB}$ of attenuation per $100 \mathrm{~m}$ at $8 \mathrm{kHz}$. The horizontal red line in the crosswind profile corresponds to the maximum acceptable winds during testing. The corresponding legend shows the maximum and average wind magnitudes relative to the allowable limits.

Identification and determination of data errors and uncertainties for full-scale acoustic measurements is a challenging task. Unlike a highly controlled wind tunnel environment, flight tests occur in uncontrolled surroundings where the local atmospheric conditions inevitably vary in time. Although local conditions were recorded every hour using a combination of weather balloon ascents and a ground station, significant local atmospheric variations could occur within a short time period. The dominance of the errors introduced by atmospheric effects (sound propagation, absorption, etc.) and pilot adjustments to the wind may, therefore, overwhelm other typical sources of error (e.g., instrumentation errors, 
etc.). To partially bracket the resulting uncertainties in the measured noise levels, repeat flights for each test condition were executed. For a small number of select configurations, repeat runs were performed on a different day to determine the day-to-day variability in the recorded noise levels.

\subsection{Test Conditions}

Given the focus of the flight test on airframe noise, the executed test matrix was targeted for approach and landing conditions. Overall, sixty-nine conditions were tested of which fifty-five were flown with aircraft engines at an approachidle setting. Table II contains a summary of the AFN conditions tested, with the calibrated airspeed KCAS given in Knots. The tested aircraft configurations can be grouped into three general categories: a) baseline, b) isolated components, and c) component interaction. The clean (cruise) and the fully deployed (landing) configurations are considered to be the baseline cases, representing the quietest and loudest airframe configurations. In addition to the baseline, the G550 (Phase I) portion of the AFN test covered several other configurations that were designed to isolate the noise sources associated with individual components (flap, nose gear, main gear, etc.). For example, the nose landing gear was pinned (locked) in place, allowing the main gear to retract while the nose gear remained deployed. A similar procedure for the main landing gear made it possible to keep the gear deployed while the nose gear was retracted. This latter condition, in conjunction with flap deflection, permits an assessment of gear-flap component interaction noise.

The nominal landing speed for the G550 aircraft is around 147 Knots $(272 \mathrm{~km} / \mathrm{hr})$. Naturally, as is evident from table II, this speed played a primary role in the executed test matrix. To attain a better understanding of the velocity scaling laws, noise measurements were acquired at three distinct speeds for most configurations. To ensure measurable changes in noise that were well above the measurement errors, these additional speeds differed from the primary speed by more than ten percent.

\begin{tabular}{|c|c|c|c|}
\hline \multicolumn{4}{|c|}{ Table II: G550 Test Sequence - Airframe } \\
\hline $\begin{array}{c}\text { Flap } \\
\text { Deflection }\end{array}$ & $\begin{array}{c}\text { Gear } \\
\text { Position }\end{array}$ & $\begin{array}{c}\text { Airspeed } \\
\sim \text { KCAS }\end{array}$ & $\begin{array}{l}\text { No. of } \\
\text { Flights }\end{array}$ \\
\hline 0 & Up & 147 & 4 \\
\hline 0 & Up & 170 & 3 \\
\hline 0 & Up & 200 & 3 \\
\hline 0 & Main only & 132 & 2 \\
\hline 0 & Main only & 147 & 2 \\
\hline 0 & Main only & 170 & 2 \\
\hline 0 & Nose only & 132 & 2 \\
\hline 0 & Nose only & 147 & 2 \\
\hline 0 & Nose only & 170 & 2 \\
\hline 0 & Full gear & 147 & 4 \\
\hline 20 & Up & 147 & 3 \\
\hline 20 & Main only & 147 & 2 \\
\hline 39 & Up & 132 & 3 \\
\hline 39 & Up & 147 & 4 \\
\hline 39 & Up & 170 & 3 \\
\hline 39 & Main only & 147 & 2 \\
\hline 39 & Nose only & 147 & 2 \\
\hline 39 & Full gear & 132 & 3 \\
\hline 39 & Full gear & 147 & 4 \\
\hline 39 & Full gear & 170 & 3 \\
\hline & & Total & $\overline{55}$ \\
\hline
\end{tabular}

\subsection{Microphone Array \& Individual Microphones}

The AFN test involved extensive noise measurements using the NASA microphone array system as well as Gulfstream free-field (certification) and aircraft mounted (surface) microphones. The microphone array measurements are useful mainly for noise source localization studies while the free field microphones provided the absolute sound pressure levels (SPL) for the different aircraft configurations tested. The setup, operation, and processing of the data collected from the free field and surface microphones were accomplished by Gulfstream engineers. The analysis of the individual microphone data followed the standard procedure typical of the aircraft certification process within the industry. 


\subsection{Array Design and Deployment}

The pattern chosen for the NASA array consisted of a non-uniform spiral clustering of 167 microphones. The pattern was optimized to provide a quasi-constant beamwidth over a wide frequency range with a minimum of $6 \mathrm{~dB}$ of side lobe suppression exhibited for all frequencies. Figure 4 depicts the microphone layout showing sensors distributed across 12 spiral arms. A single microphone was placed at the center of the pattern, defined as the phase center of the array. A 3-degree spiral angle and random angular perturbation were applied to each arm. The purpose of the random perturbation was to enhance side lobe suppression. The radius of each ring of microphones in the pattern was defined to be twice that of the adjacent inner ring. This arrangement was chosen to facilitate the future use of frequency-invariant beam width weighting algorithms such as those used by Brooks et al. ${ }^{11}$ and subsequently by Humphreys et al. ${ }^{12}$ The natural response (i.e., unweighted) 3 -dB beamwidths of the array for sources located 300, 400, and 600 feet in front of the central microphone are shown in Fig. 5.

The sensors employed for this study were Panasonic WM-61A omni-directional electret microphones, mounted on individual printed circuit boards measuring 3 by 3 inches. These particular sensors exhibit a nominal sensitivity of 15 $\mathrm{mV} / \mathrm{Pa}$ with a relatively flat pressure response to $20 \mathrm{kHz}$. The microphones were deployed on the paved (asphalt) overrun segment of runway 4 as shown in Fig. 6. The center microphone plus the 48 innermost microphones were mounted on a rigid metal plate with the center of the plate positioned at a precise GPS surveyed location. The remaining microphones were mounted individually on circular plexiglass mounting platters approximately 0.75 inches thick and 16 inches in diameter. These platters contained a square recessed cutout for mounting the microphone and printed circuit board. A plastic cover and piece of metal tape with a pinhole were positioned over the platter-mounted microphones to provide a flush surface. Two distinct procedures were followed to accurately map the coordinates of each microphone relative to the center of the array. In one approach, a direct GPS survey of each microphone's location was performed. In the second approach, the microphone locations were determined using a standard surveyor's transit. Both procedures provided microphone positions that matched their desired locations to better than one inch. A solid cover plate was placed on the central microphone mounting plate and small plastic traffic cones were placed on the center of each of the platters to protect the microphones from the weather when the array was not in use.

A highly distributed acquisition system was used to acquire time history data from the array. The acquisition hardware was previously used to collect wake vortex acoustic data at the Denver International Airport in $2003{ }^{13}$, with the system subsequently modified for the present study. Six remote computers each containing four 8-channel, 16-bit data acquisition cards were housed along the perimeter of the array in three climate-controlled enclosures. These enclosures also housed commercially available signal conditioning amplifiers and filters. A 10-baseT Ethernet network connected the signal conditioners and remote computers to a central computer housed in the NASA data van situated next to runway 4. Synchronization of all remote computers was accomplished using a timing system employing low-voltage differential signaling, with one remote computer serving as the master. To verify that simultaneous sampling was being performed properly by the array, one channel of each data acquisition card was connected to a low-frequency square wave. Phase variances between the various acquisition channels could be easily detected via inspection of the acquired square wave time histories. Finally, a single data acquisition channel was connected to a GPS IRIG-B time code generator housed in the enclosure containing the remote master computer. The array time stamps were matched with similar ones generated onboard the aircraft to synchronize the array and flight recorder time bases.

A typical data acquisition cycle lasted 30 seconds and was started when the test aircraft passed a visual reference marker. All microphone channels were uniformly sampled at a $76.8-\mathrm{kHz}$ rate, and a real-time display of microphone time history data was transmitted to the master computer in the data van to facilitate monitoring the performance of the array. Low pass filtering at a $25-\mathrm{kHz}$ cutoff frequency was performed for all microphones, and a post filter gain setting of x20 $(13 \mathrm{~dB})$ was employed. The acquired time history data from the array were stored on local hard drives in the remote computers and relayed to the master computer in the acquisition data van for permanent archiving at the end of a set of aircraft flyover runs.

\subsection{Individual Microphones}

As shown in Fig. 6, the three Gulfstream microphones were located adjacent to the overrun area. The center of the NASA array was used as the reference location and defined along the flight path of the aircraft at $(0,0,0)$. The primary Gulfstream microphone was located $140 \mathrm{ft}(42.7 \mathrm{~m})$ upstream of this point, while a secondary microphone was located 10 $\mathrm{ft}(3 \mathrm{~m})$ downrange of the primary in the direction of the flight path. The intent was to use noise measurements from the secondary microphone as a backup only if a measurement from the primary microphone was faulty. Both were mounted with the microphone diaphragms placed $4 \mathrm{ft}(1.2 \mathrm{~m})$ above the ground. The third microphone was mounted at ground level and was used to detect the presence of pseudo-tones. 
Each microphone system consisted of the microphone, preamplifier, tripod, cable and power supply. Additionally, the specific tape recorder channels were assigned to each system to ensure integrity throughout the test. Bruel \& Kjaer (B\&K) model 4193 1/2-inch pressure response microphones were used with B\&K model 2669 preamplifiers on all systems. In addition, the initial time code event generated was transmitted by VHF to the ground station and was recorded on one recorder channel, to permit time coordination with the airplane position and aircraft operating parameters.

\section{$4.3 \quad$ Surface Microphones}

In addition to the individual microphones on the ground, three other microphones were mounted on the surface of the aircraft by the Gulfstream Flight Sciences group. These microphones were installed at locations deemed to produce significant levels of flow unsteadiness and thus high amplitude surface pressure fluctuations. Of the three microphones, one was placed on the rear vertical strut of the main landing gear (Fig.7a). A second microphone was positioned on the aft door of the nose gear (Fig.7b). The third microphone was installed on the rear wall of the nose gear cavity.

The surface microphones were B\&K type 4948B having a sensitivity of $1.4 \mathrm{mV} / \mathrm{Pa}$, a frequency range of $5 \mathrm{~Hz}$ to $20 \mathrm{kHz}$, and a dynamic range of 55 to $160 \mathrm{~dB}$. Care was taken to ensure that the microphones were positioned in such a way not to disturb the local flow field significantly or generate unusual wakes or vortices. The step around the edge of the microphone was faired to minimize flow disturbance by the microphone. The fairing has a fineness ratio of 10, resulting in a diameter of 4.5 inches. Due to their size, the fairings were conformal to the aircraft surface where they were mounted.

\section{$4.4 \quad$ Array Processing}

Post-processing of the array measurements was conducted using the conventional delay and sum technique in the time domain ${ }^{14}$. To account for the Doppler effects and short time records in flight tests, researchers at NASA LaRC developed a new beamforming program to process the array data. Boeing engineers provided extensive guidance on the basic algorithm and aided the AFN team in successfully testing and validating the program with Boeing array data. The program was then modified to use the data formats of the NASA data acquisition system. Beamforming was performed on a square, planar grid of $130 \mathrm{ft}(39.6 \mathrm{~m})$ using $81 \times 81$ grid points. The location of the grid was prescribed by the DGPS data describing the location of the aircraft. Because the beamforming was performed in the time domain, the weights for the blending had to be applied during the delay-and-sum process. For each frequency range of interest, the weighting and delay-and-sum had to be performed followed by a direct Fourier transform to obtain the Fourier coefficient of interest. Computations were performed to generate beamform image maps. Microphones were weighted to effectively reduce the array size as the frequency increased, thereby minimizing difficulties if outer microphones became decorrelated. Atmospheric corrections were applied assuming the air properties and velocities were uniform between the aircraft and the ground. The conditions were linearly interpolated in time from the hourly weather balloon measurements, which were averaged over the altitude. The wind velocities were incorporated into the beamforming, and the atmospheric conditions were used in the absorption model of Bass et al. ${ }^{15}$. Additionally, the results were scaled to an altitude of $394 \mathrm{ft}(120 \mathrm{~m})$ assuming spherical spreading for pressure $\left(\mathrm{p}^{, 2} \sim 1 / \mathrm{r}^{2}\right)$.

\subsection{Ground Microphone Processing}

Post-processing of the ground microphones followed conventional practices derived from noise certification. One notable modification from conventional noise certification processing preserves the integrity of the individual SPL values for each $1 / 2$-second sample, rather than using the slow response, which involves a weighting of sequential time intervals. The recorded data for each $1 / 2$-second interval throughout the flyover were analyzed into $1 / 3$-octave bands. These were time-correlated with the airplane space position using DGPS information. The resulting information was corrected to the reference flight path for an altitude of $394 \mathrm{ft}(120 \mathrm{~m})$ assuming spherical spreading $\left(\mathrm{p}^{, 2} \sim 1 / \mathrm{r}^{2}\right)$ and atmospheric absorption.

\section{Results and Discussion}

For each configuration, noise measurements were obtained at three distinct speeds with multiple runs at each speed in order to improve the statistical quality of the data acquired. We begin by presenting the source localization (beamform) maps which are useful mainly for detecting the regions where the dominant airframe noise sources reside. Given the large number of conditions tested, it is impractical to display the entire collection of the beamform maps generated. Therefore, only select configurations at a nominal speed of 147 knots are discussed here. It suffices to mention that these results are also representative of the airframe noise sources at the other two (132 and 170 knots) airspeeds. Only results for the time duration corresponding to emission angles of 76 to 90 degrees relative to flight direction are presented. The flight configurations discussed in this paper were selected to highlight the more prominent airframe noise sources. The six selected configurations are: a) flaps deployed at 39 degrees and gear down (landing configuration), b) flaps retracted and gear up (cruise/clean configuration), c) flaps deployed at 39 degrees and gear up, d) flaps retracted and only 
main gear down, e) flaps retracted and only nose gear down, and f) flaps deployed at 39 degrees and only main gear down. Note that the G550 aircraft does not possess a leading edge slat; therefore, slat noise is not relevant for this study.

\subsection{Beamform Contour Maps}

Sample source localization (beamform) contour maps for the landing condition (flaps 39, gear down), representing the noisiest airframe configuration, are shown in Fig.8. To enhance the visualization of the noise sources, the dynamic range in the maps is restricted to $8 \mathrm{~dB}$ below the peak levels at each frequency. The orientation of the maps is from the point of view of an observer standing on the ground looking up at the under surface of the aircraft. The slight misalignment between the source maps and the aircraft outline is due to the cumulative effect of atmospheric winds. No attempt has been made to remove this misalignment via translation and rotation of the source maps. Figure 8 highlights the noise sources for this condition at frequencies of $1335 \mathrm{~Hz}$ and $3092 \mathrm{~Hz}$. The prominent sources are associated with the flap and the main gear. The nose landing gear is a weaker source with levels that are 2-3 dB below the flap and main gear sources. For frequencies below $1500 \mathrm{~Hz}$, the flap outboard side edges are the more dominant sources. Above $1500 \mathrm{~Hz}$, the combination of the inboard side edges plus the main gear become the stronger source and produce higher noise levels relative to the flap outboard edges. The physical proximity of the main gear to the inboard flap side-edge makes it challenging to isolate the two sources and determine which one is the more dominant source. In fact, it is quite plausible that gear-flap interaction may cause the noise to be at higher levels than that of the individual sources. A sample map for the other baseline (cruise) configuration at $1595 \mathrm{~Hz}$ is displayed in Fig.9. As suspected, the contour plot (which is typical of the maps at other frequencies for this configuration) shows no evidence of airframe noise sources. The only visible noise source is the residual engine noise that mostly shows up in the vicinity of the inlet and jet exhaust planes.

The contour maps for the flaps 39, gear up configuration at $1074 \mathrm{~Hz}$ and $1335 \mathrm{~Hz}$ are plotted in Fig.10. This test condition was flown to isolate the noise sources associated with the aircraft high-lift (flap) system. Similar to past results for mid- and large-size civil transport, the noise sources associated with the flap side edges show up as the most dominant. However, scrutiny of the beamform maps at other frequencies revealed the outboard edge to be the more prominent of the two sources for frequencies up to $3500 \mathrm{~Hz}$, showing up in most contours while the inboard source is present only at selected frequencies. For the frequency range above $3500 \mathrm{~Hz}$, an opposite trend takes place and the inboard edge becomes the primary source. Overall, the flap side edges are robust noise sources, radiating over a wide range of frequencies.

Figure 11 displays the maps at $553 \mathrm{~Hz}, 1335 \mathrm{~Hz}$, and $4004 \mathrm{~Hz}$ for the configuration where only the main gear was deployed. At the low- to mid-frequency range, the main gear shows up as a strong source with levels that are nearly $8 \mathrm{~dB}$ above the background and other sources. At frequencies above $3500-4000 \mathrm{~Hz}$, the residual engine noise gradually begins to appear in the contour maps, although the main gear still remains as the primary source. Similar trends are observed when the nose landing gear is isolated (Fig.12), indicating that the main gear and the nose gear sources could very well have comparable strength. Although not shown, scrutiny of the source maps for the configuration where both gears were deployed with flaps retracted corroborated this conjecture and showed the main and nose gears as competing sources.

The test configuration devoted to highlighting component interaction noise (flaps 39 and only main gear down) produced source maps that, minus the nose gear source, are very similar to the maps for the landing configuration discussed above. Therefore, their presentation is omitted here.

\subsection{Free-Field Microphones}

Processing of the free-field microphone data to extract the noise levels was accomplished by Gulfstream engineers. This initial round of processing includes corrections to account for absorption and propagation effects due to the variation in the local atmospheric conditions. Furthermore, the processed data account for the variations in the aircraft speed and altitude from the nominal values. Assuming spherical spreading of the radiated noise and a $\mathrm{U}^{6}$ velocity dependence for the noise levels, the post processed 1/3-octave band spectra have been normalized to a common altitude of $394 \mathrm{ft}$ (certification height) and aircraft speed of 147 knots. However, the corresponding minor shift in the frequencies due to Strouhal scaling (less than $2 \%$ in most instances) was omitted during the normalization step.

As an indicator of data repeatability, a sample plot of the measured SPL spectra at 147 knots for the flaps 39 and landing gear up configuration is displayed in Fig.13. Three repeat runs (conducted on the same day and normalized to a common altitude and speed), plus the average spectrum associated with this configuration are plotted. The figure indicates that good repeatability was achieved. On average, the results for other configurations under consideration show more or less similar collapse of the repeat data. Day-to-day variation in the measured SPL mostly shows up in the higher frequencies (above 3-4 kHz) where the levels are typically 10-15 $\mathrm{dB}$ below the maximum band level, and the influence of variability in atmospheric conditions, especially absorption, is a more dominant factor. 
The SPL levels for five of the selected conditions are plotted in Fig. 14. Each curve represents the averaged value of all of the acceptable runs conducted for that particular configuration. Comparison of the levels for the two extremes corresponding to landing (square symbols) and clean (circles) configurations shows the noise contribution from the deployed flaps and the undercarriage to be on the order of 6-10 dB over the low- and mid-frequency range. Due to atmospheric conditions and higher background noise on some of the test days, noise levels for frequencies above $4 \mathrm{kHz}$ must be viewed with suspicion as it is evident from crossing of the curves for clean and landing configurations. Given that all the flights were executed with an approach-idle engine setting, Fig.14 shows the residual engine noise not to be a factor. Moreover, except for the presence of a dominant narrow-band noise source (although strictly not correct, from hereafter, for simplicity we will call this type of feature in the spectra a tone) at $790 \mathrm{~Hz}$, the main landing gear contributes less to the total noise than the flaps. Closer examination of the beamform maps for the landing configuration revealed that the tone was originating from the main gear on the starboard side, having a frequency that is between $680 \mathrm{and} 750 \mathrm{~Hz}$. This tone is certainly strong as the beamform maps showed no other visible airframe sources within $8 \mathrm{~dB}$ of the tonal peak. Next, to reconfirm the presence of the tone emanating from the starboard gear, beamform maps for the configuration with flaps retracted and only the main gear down were examined. Interestingly, for this configuration, the maps now pointed to a $700 \mathrm{~Hz}$ tone on the main gear but on the opposite (port) side. One can attribute this switch in the tone location to the flap deflection, minor differences in the aircraft conditions (e.g., presence of yaw, differences in glide slope and pitch angle, etc.), and/or variability in the atmospheric conditions from run to run. However, we do not have a clear explanation yet as to what causes this change in tone location.

In addition to the main gear tone, there is one other prominent and two minor tones in the spectrum for the landing configuration (square symbols in Fig. 14). The primary tone at $200 \mathrm{~Hz}$ and the secondary tone at $315 \mathrm{~Hz}$ are visible in all the spectra, regardless of the configuration tested. Therefore, they cannot be viewed as typical noise sources generated by flap or landing gear deployment. Unfortunately, the spatial resolution of the array at these lower frequencies is insufficient to determine the exact locations of these two sources. The other secondary tone occurs at $1100 \mathrm{~Hz}$, and it is clearly attributable to flap deployment (Fig.13). The corresponding beamform maps (Fig.10) reveal that the tone originates from the outboard edges of the flaps. Similar source maps were obtained for the landing configuration indicating that, at frequencies between 1000 and $1200 \mathrm{~Hz}$, the tone is nearly 6-8 dB louder than those generated by other airframe noise sources.

To determine the scaling laws for the dominant airframe noise sources, most configurations of interest were tested at three distinct speeds. The SPLs for the noisiest (landing) configuration at 132, 147, and 170 knots are shown in Fig. 15a. Two prominent features are apparent in the spectra. First, the main gear tone $(790 \mathrm{~Hz})$ disappears at the lowest speed. Examination of the SPL for the case of flaps retracted and only main gear deployed confirmed the presence of the tone at 132 knots. It needs to be determined whether gear-flap interaction at the lower speed has altered the tone. At present, we do not have a viable explanation for the tone disappearance. A second feature in Fig. 15a involves the frequencies for the tones at 180,320, and $790 \mathrm{~Hz}$. Notice that these frequencies remain unchanged even though aircraft speed is varied by more than $10 \%$ from the nominal speed of 147 knots. Certainly, if these tones were flow induced, one would expect a frequency shift proportional to the speed ratio (Strouhal scaling). Our attempt to normalize the SPL spectra using a velocity to the sixth power $\left(\mathrm{U}^{6}\right)$ scaling of the amplitude, and Strouhal scaling of the frequency did not collapse the measured spectra at different speeds. Better collapse was obtained by omitting the Strouhal scaling of the frequencies (Fig. 15b). Preliminary analysis of SPLs for isolated components (e.g., main gear, flaps) also showed the inappropriateness of normalizing the frequencies according to speed variation. The absence of Strouhal scaling for the sound pressure levels is puzzling. We do not have a clear explanation during this preliminary round of analysis.

\subsection{Surface Microphones}

Most semi-empirical acoustic models of landing gear noise in use today assume the presence of vortex shedding from gear struts. We begin this section with the discussion of the measured pressure fluctuations from the surface microphone mounted on the main gear's rear strut. This particular location was chosen to determine whether landing gear struts produce tones, particularly when they are in close proximity to other gear components. The microphone signals were acquired with a $24 \mathrm{kHz}$ sampling rate providing a frequency bandwidth of $10 \mathrm{kHz}$. For analysis purposes, record lengths of 9 seconds have been used. The time records provided 52 blocks of 4096 samples for computing the spectral averages, providing a frequency resolution of $5.86 \mathrm{~Hz}$.

The power spectral density (PSD) plots of the surface pressure fluctuations are presented in Fig. 16a. These particular measurements were obtained during the runs for the landing configuration. For clarity, only two runs at each aircraft speed are displayed. The pressures have been normalized to a common aircraft speed of 147 knots, using the dynamic-head $\left(1 / 2 \rho \mathrm{U}^{2}\right)$ ratio as the scaling factor. As in the case of sound pressure levels, better collapse of data is obtained by omitting Strouhal (St) scaling of the frequencies. Thus, the frequencies in Fig.16a are not scaled. The normalized pressure spectra collapse reasonably well, but we must point out that the collapse is not much better than that 
obtained with the unnormalized spectra. More importantly, the measured spectra show the pressure field to have a broadband character lacking any prominent tonal component. However, the peak in the normalized spectrum occurs in the vicinity of $100 \mathrm{~Hz}$, which is very close to the strut's shedding frequency, assuming St=0.24 and an aircraft speed of 147 Knots. The absence of a strong tonal feature can be attributed to two factors. Primarily, for short spacing between two tandem cylinders, it is well known that the shedding process is significantly weakened ${ }^{16}$. Thus, the presence of the

forward (upstream) strut may very well have altered the shedding process on the rear strut. Secondarily, for the range of speeds under consideration, the Reynolds number based on the diameter of the rear strut is between $4.5 \times 10^{5}$ and $6.5 \times 10^{5}$. This range falls within the supercritical flow regime where the shedding process in the wake of an isolated circular cylinder ceases to be organized.

The PSD plots for the microphone planted on the aft door of the nose gear are shown in Fig. 16b. A similar normalizing procedure as that described above was also applied to these pressures. The normalized spectra collapse into a single curve, although the collapse is not as tight as that observed for the main gear spectra. As in the main gear case, the normalized spectrum shows a broadband character and lacks any dominant tonal features. This is in spite of the fact that flow passes over the nose gear lighting system, vertical strut, and the steering mechanism before reaching the microphone position on the aft door. As shown in Fig. 16b, the spectrum does possess the drop in pressure amplitude around $100 \mathrm{~Hz}$. The highest amplitude fluctuations occur below this frequency but, from the noise point of view, they are less relevant.

\section{Conclusions}

In a partnership between NASA and Gulfstream, G550 and G450 aircraft were flown to collect baseline airframe noise measurements on a regional jet class of transport. The extensive test matrix was devised to characterize the acoustic spectra associated with both the full aircraft and individual airframe components. NASA's microphone array, comprising of 167 microphones, was deployed to provide the source localization maps for frequencies between $200 \mathrm{~Hz}$ and $8 \mathrm{kHz}$. Gulfstream's individual microphones were deployed on the ground and on both main and nose gear surfaces to collect sound pressure levels and record near-field hydrodynamic pressure fluctuations. Initial analysis of the test results confirmed that the airframe is a major contributor to the noise from regional jets during landing operations.

The present preliminary analysis of the acquired acoustic data was devoted to the Phase I results involving the G550 test aircraft. Comparison of the SPL for airframe configurations of highest interest indicates that the flap system is the most dominant airframe noise source with levels that are 3-4 $\mathrm{dB}$ above the gear noise levels for most frequencies. The array beamform maps show that most of the radiated sound from the flaps originates from the side edges, with the outboard edges being more prominent for frequencies below $1500 \mathrm{~Hz}$ and the inboard edges being the stronger source of noise at higher frequencies. The SPL spectra for both the landing configuration and the configuration isolating the main gear revealed a dominant narrow-band noise source within the $650-800 \mathrm{~Hz}$ frequency band. The corresponding beamform maps confirmed the presence of the main gear tone. However, depending on whether the flaps were deployed or retracted, the spatial origin of this tone toggled between the main gear on the starboard side and port side. A clear explanation for this switching of the tone location has yet to be found. Other than this tone, the main gear and the nose gear contribute equally to the aircraft noise over most of the frequency range.

Using $\mathrm{U}^{6}$ and Strouhal scaling of the SPL spectra obtained at different speeds failed to collapse the data into a single spectrum. The best data collapse was obtained when the frequencies were left unscaled. The surface pressure spectra from microphones mounted on the main-gear rear strut and the aft door of the nose gear showed a broadband character lacking any tonal components. Normalization of the surface pressure spectra at different speeds was accomplished using the dynamic-head ratio, thus highlighting the hydrodynamic nature of the near-field pressure fluctuations. As in the SPL spectra, much improved data collapse was observed when the scaling of the frequencies was omitted. The underlying cause for this lack of Strouhal scaling for both far-field noise and near-field pressure fluctuations is unknown at the moment, but it deserves serious consideration in the future.

\section{Acknowledgements}

As is the case for any flight test, there were numerous (too many to be listed here) coworkers whose behind-thescenes contributions made the AFN test a success. To those, we express our sincerest gratitude. We also would like to acknowledge the critical contributions of Scott Bartram, Charles Howell, George Beeler, John Swain, and Lucille Crittenden of NASA Langley Research Center and John Dickerson, Edward Sudendorf, and Wayne Johnston of NASA Wallops Flight Facility and Chip King, Robert Wilfert, and Christopher Babcock of Gulfstream Aerospace Corporation.

\section{References}

1. Michel, U., Barsikow, B., Helbig, J., Hellmig, M., and Schüttpelz, M., "Flyover noise measurements on landing aircraft with a microphone array", AIAA Paper 98-2336, May 1998. 
2. Piet, J.-F., Elias, G., and Lebigot, P., "Localization of acoustic sources from a landing aircraft with a microphone array," AIAA Paper 99-1811, 1999, 5th AIAA/CEAS Aeroacoustics Conference, Bellevue, Washington, USA, May 1012,1999

3. Michel, U., and Qiao, W., "Directivity of Landing-Gear noise Based on Flyover Measurements". AIAA-99-1956, 5th AIAA/CEAS Aeroacoustics Conference, Bellevue (Greater Seattle), WA, May 10-12, 1999.

4. Pott-Pollenske, M., Dobrzynski, W., Buchholz, H., Gehlhar, B., Walle, F., "Validation of a Semiempirical Airframe Noise Prediction Method through Dedicated A319 Flyover Noise Measurements", AIAA Paper 2002-2470,

Breckenridge,CO, 2002.

5. Stoker, R., Guo, Y., Streett, C., and Burnside, N., “Airframe Noise Source Locations of a 777 Aircraft in Flight and Comparisons with Past Model Tests,” AIAA Paper 2003-3232, Hilton Head, SC, 12-14 May, 2003.

6. Sijtsma, P. and Stoker, R., "Determination of Absolute Contributions of Aircraft Noise Components Using Fly-Over Array Measurements," AIAA paper 2004-2958, 10th AIAA/CEAS Aeroacoustics Conference, Manchester, United Kingdom, 10-12 May, 2004,.

7. Piet, J-F, Davy, R., Elias, G. and Siller, H. A., Chow, L.C., Seror, C., and Laporte, F.,"Flight Test Investigation of Add-On Treatments to Reduce Aircraft Airframe Noise," AIAA Paper 2005-3007, Monterey, CA, 23-25 May, 2005.

8. Elkoby, R., Brusniak, L., Stoker, R., Khorrami, M.R., Abeysinghe, A., and Moe, J.W., "Airframe Noise Results from the QTD II Flight Test Program,” AIAA Paper 2007-3457, Rome, Italy, May, 2007.

9. Fethney, P., “An Experimental Study of Airframe Self-Noise," AIAA Paper 75-511, AIAA $2^{\text {nd }}$ Aeroacoustics Conference, Hampton, VA, 24-26 March, 1975.

10. Bauer, A.B. and Munson, A.G., “Airframe Noise of the DC-9-31,” NASA Contractor Report 3027, July, 1978.

11. Brooks, T.F., Marcolini, M.A., and Pope, D.S., "A Directional Array Approach for the Measurement of Rotor Noise Source Distributions with Controlled Spatial Resolution", Journal of Sound and Vibration, Volume 112, Number 1, pp. 192-197, 1987.

12. Humphreys, W. M., Jr., Brooks, T. F., Hunter, W. W., Jr., and Meadows, K. R., "Design and Use of Microphone Directional Arrays for Aeroacoustic Measurements", AIAA Paper 98-0471, 36 ${ }^{\text {th }}$ Aerospace Sciences Meeting and Exhibit, Reno, NV, 1998.

13. Dougherty, R. P., Wang, F. Y., Booth, E. R., Jr., Watts, M. E., Fenichel, N., D’Errico, R. D., "Aircraft Wake Vortex Measurements at Denver International Airport," AIAA Paper 2004-2880, $10^{\text {th }}$ AIAA/CEAS Aeroacoustics Conference, Manchester, Great Britain, 2004.

14. Dougherty, R., "Advanced Time-Domain Beamforming Techniques," AIAA-2004-2955, Presented at the 10th AIAA/CEAS Aeroacoustics Conference, Manchester, UK, May 10-12, 2004.

15. Bass, H. E., Sutherland, L. C., Zuckerwar, A. J., Blackstock, and D. T., Hester, D. M., "Atmospheric absorption of sound:Further developments," Journal of the Acoustical Society of America, 97(1), pp. 680-683, January, 1995.

16. Zdravkovich, M. M., "Review of Flow Interference Between Two Circular Cylinders in Various Arrangements," J. Fluids Engineering, Vol., pp. 618-633, December 1977. 


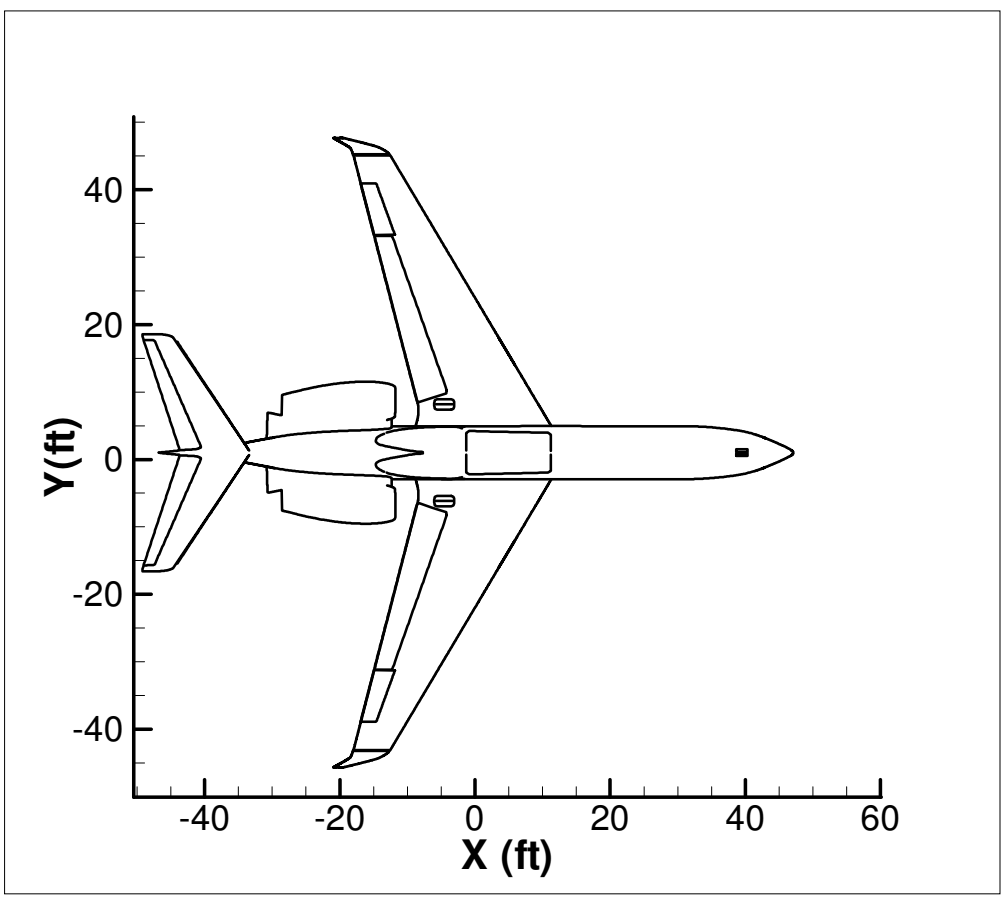

Fig. 1. G550 aircraft outline

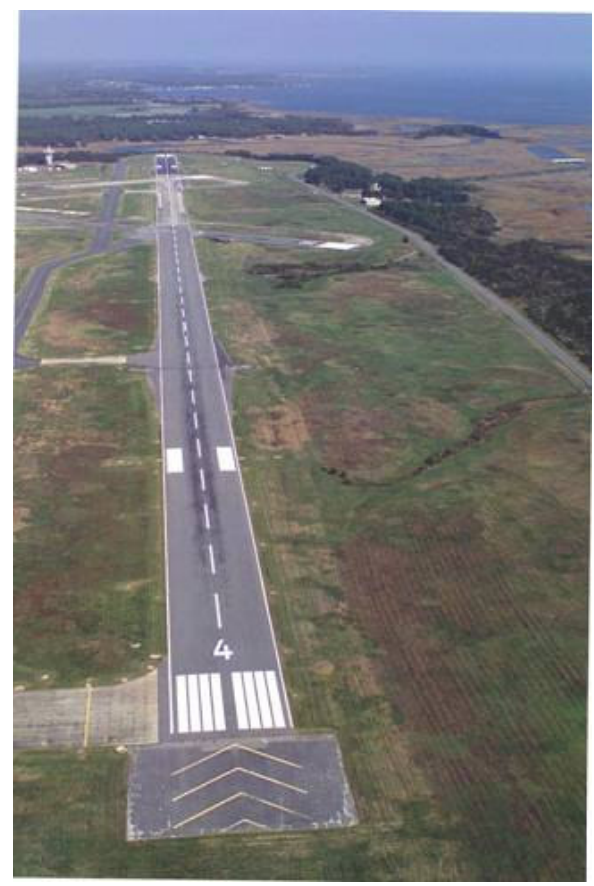

Fig. 2. South-end aerial view of runway 4 at Wallops Flight Facility 

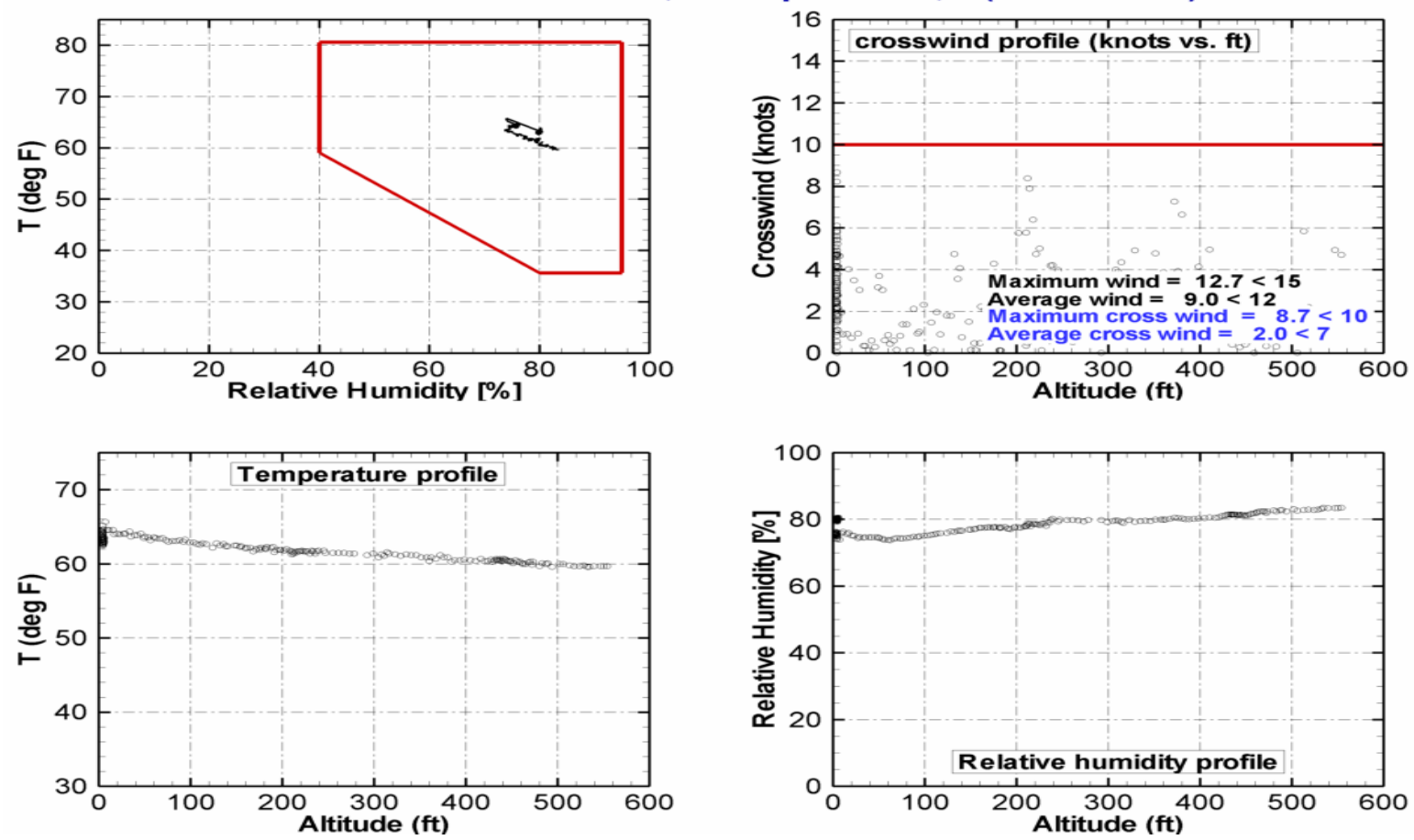

Fig. 3. Sample profiles of measured quantities from weather balloon.

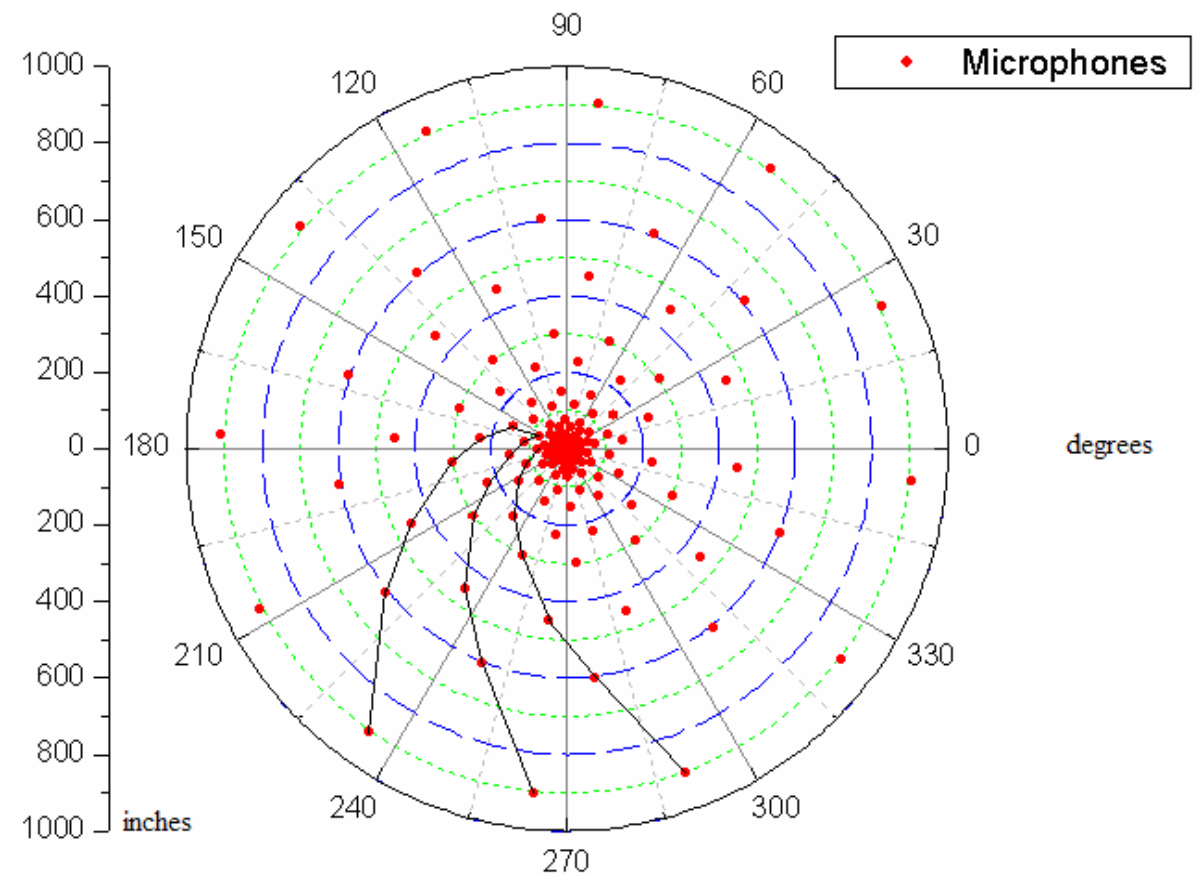

Fig. 4. Array sensor locations. Three spiral arms depicted. 


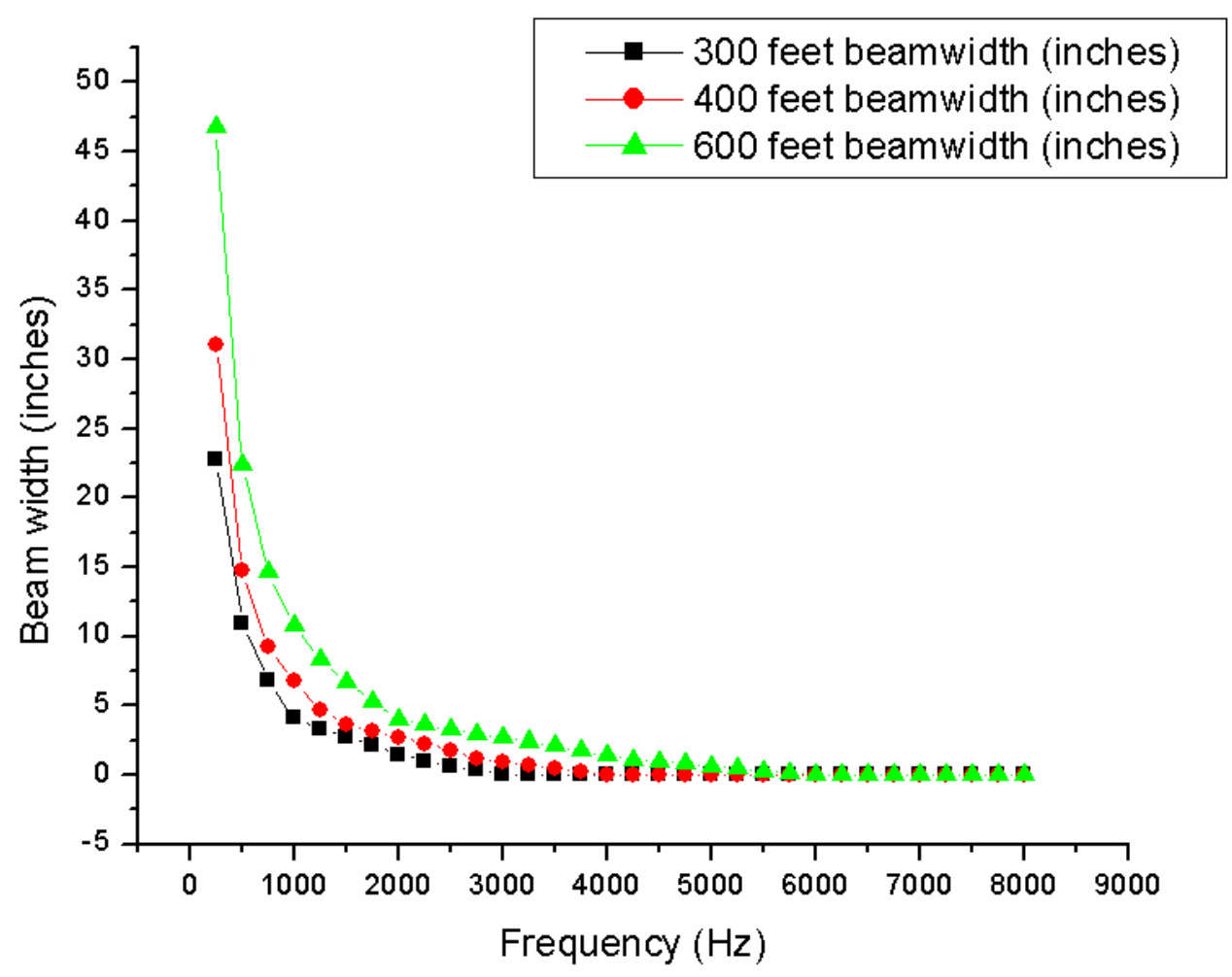

Fig. 5. 3-dB beamwidth of unshaded array.



Fig. 6. NASA Wallops Flight Facility runway 04 overrun area layout. 


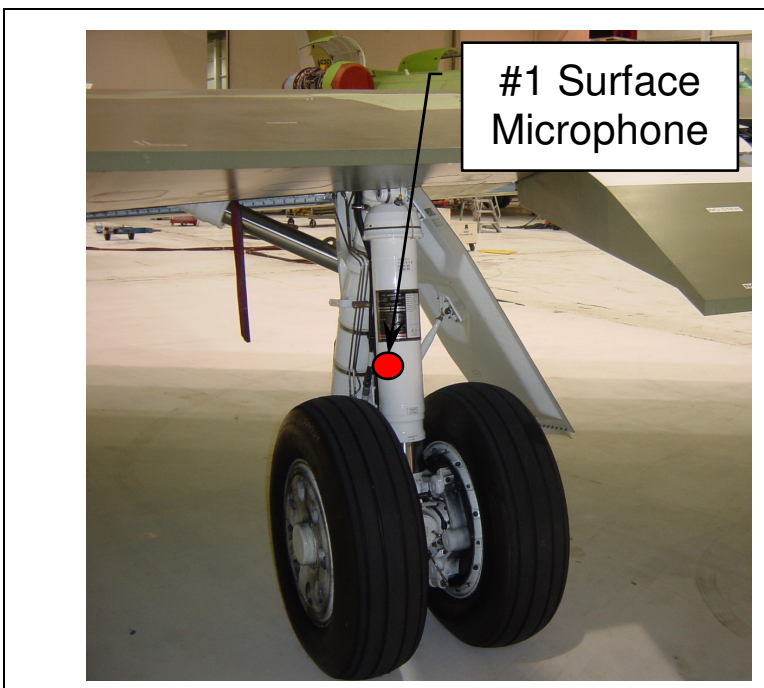

a) main gear rear strut

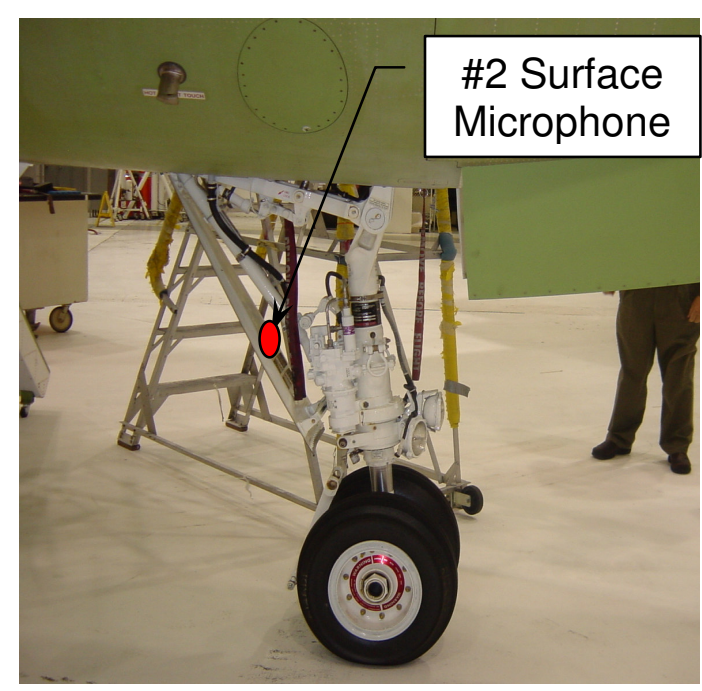

b) nose gear aft door

Fig. 7. Locations of gear mounted surface microphones
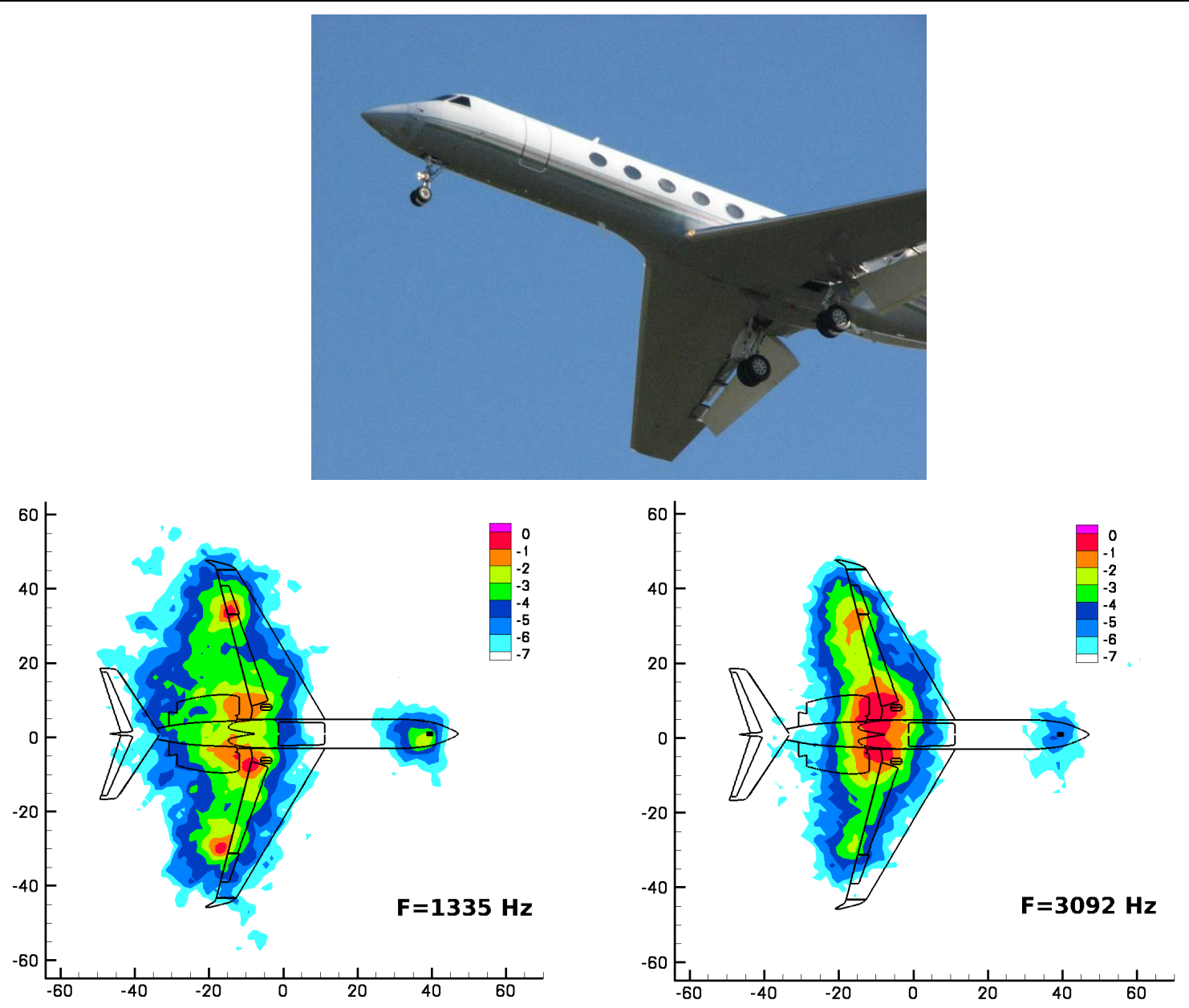

Fig. 8. Source localization maps for flaps 39, gear down (landing) configuration 

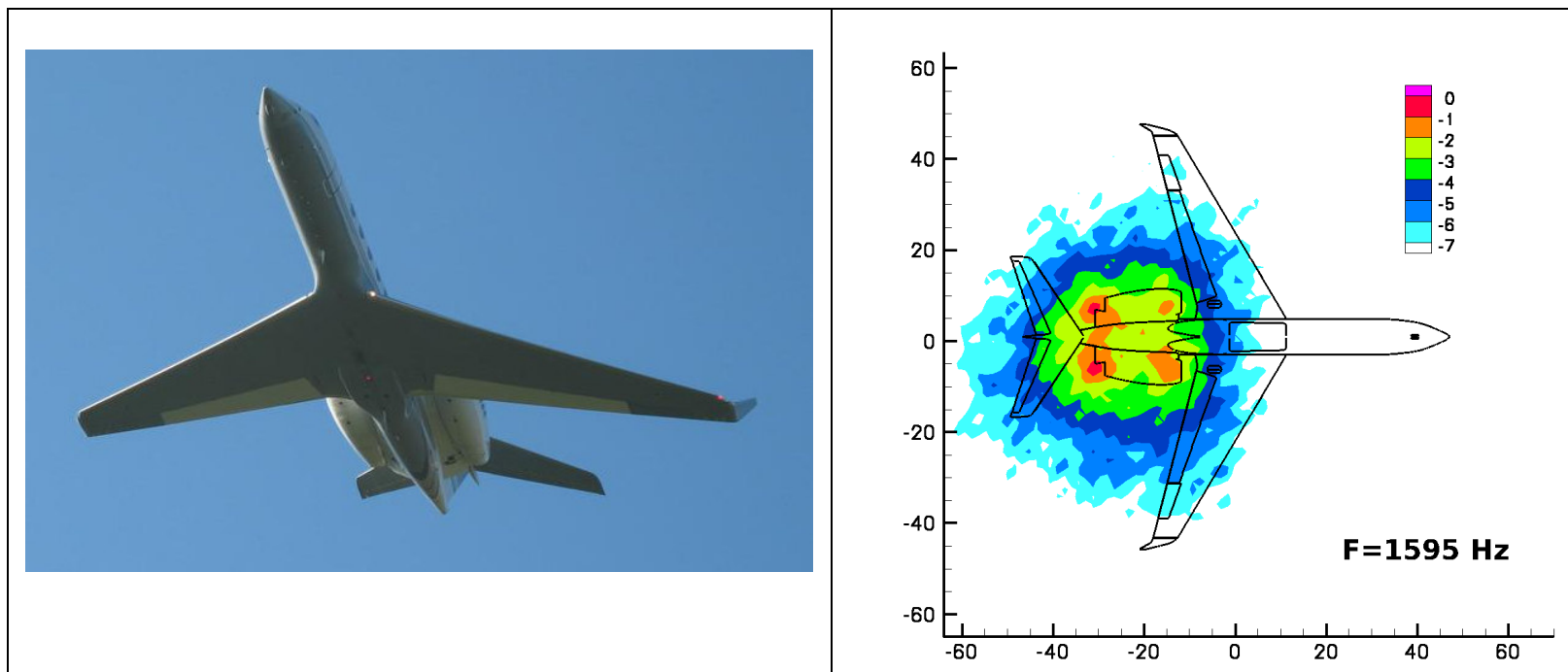

Fig. 9. Source localization map for flaps 0 , gear up (clean) configuration at 147 knots

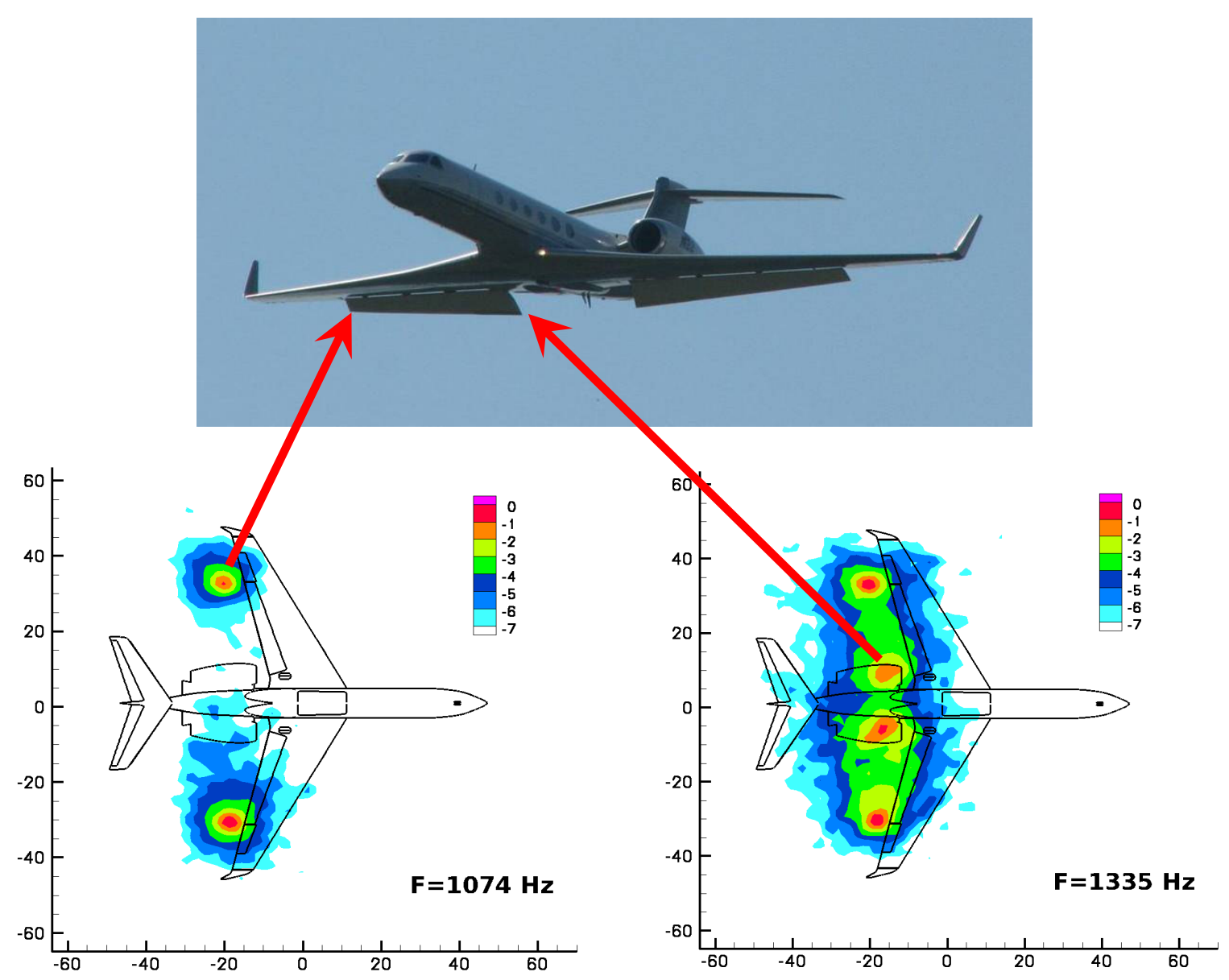

Fig. 10. Source localization maps for flaps 39, gear up configuration at $1074 \mathrm{~Hz}$ and $1335 \mathrm{~Hz}$ 


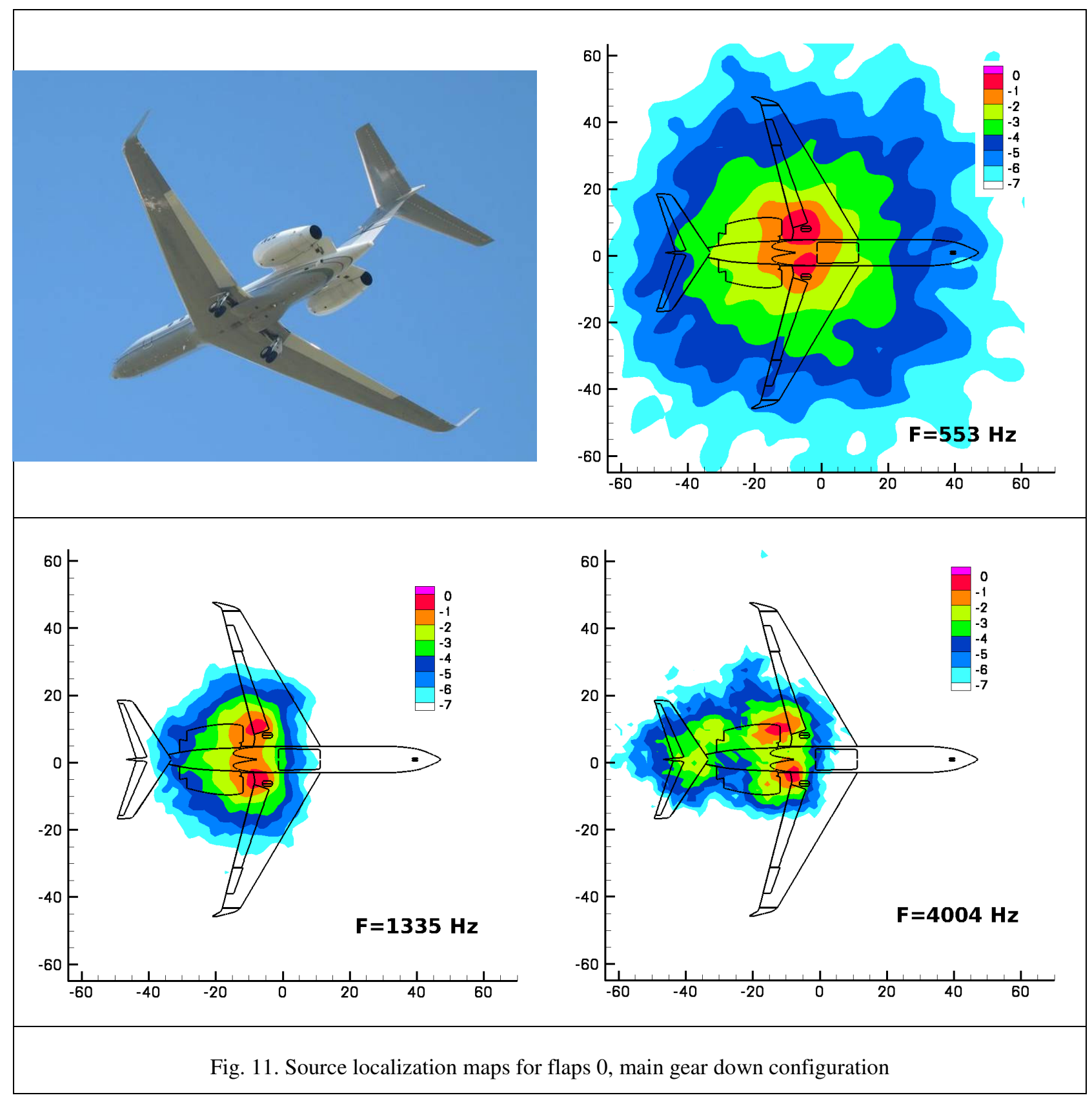









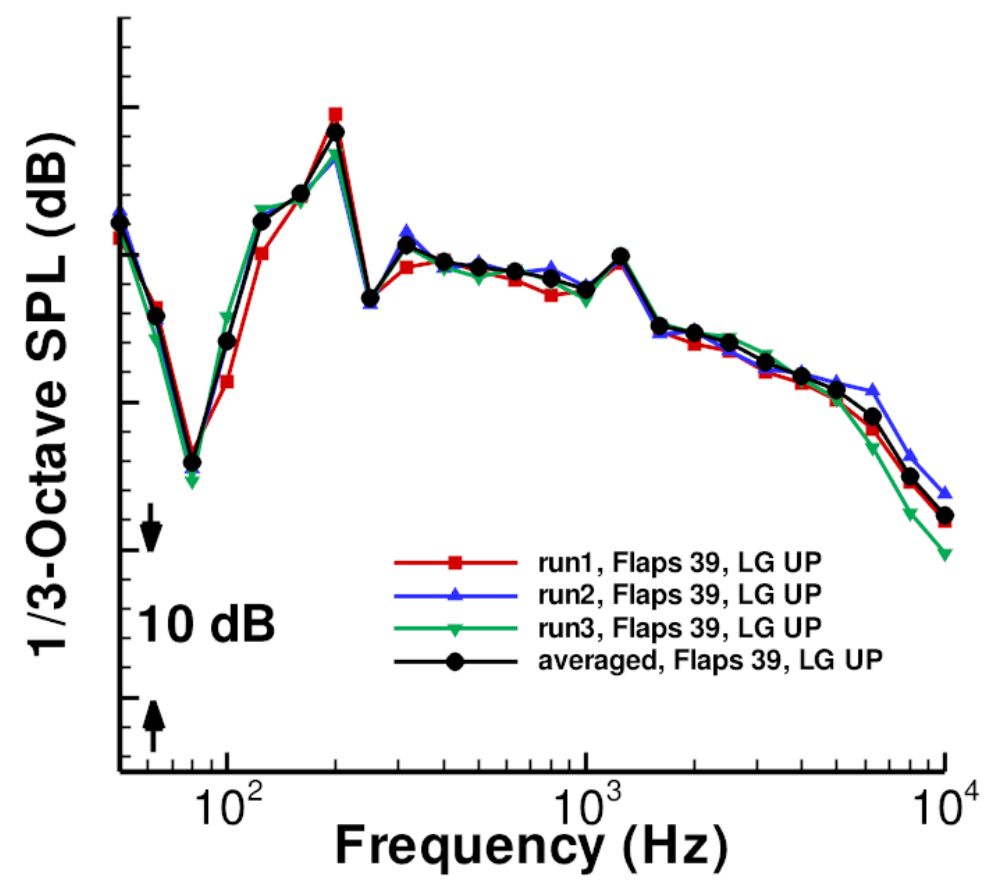

Fig.13. Spectra from repeat runs at 147 knots showing good collapse of measured data for flap noise

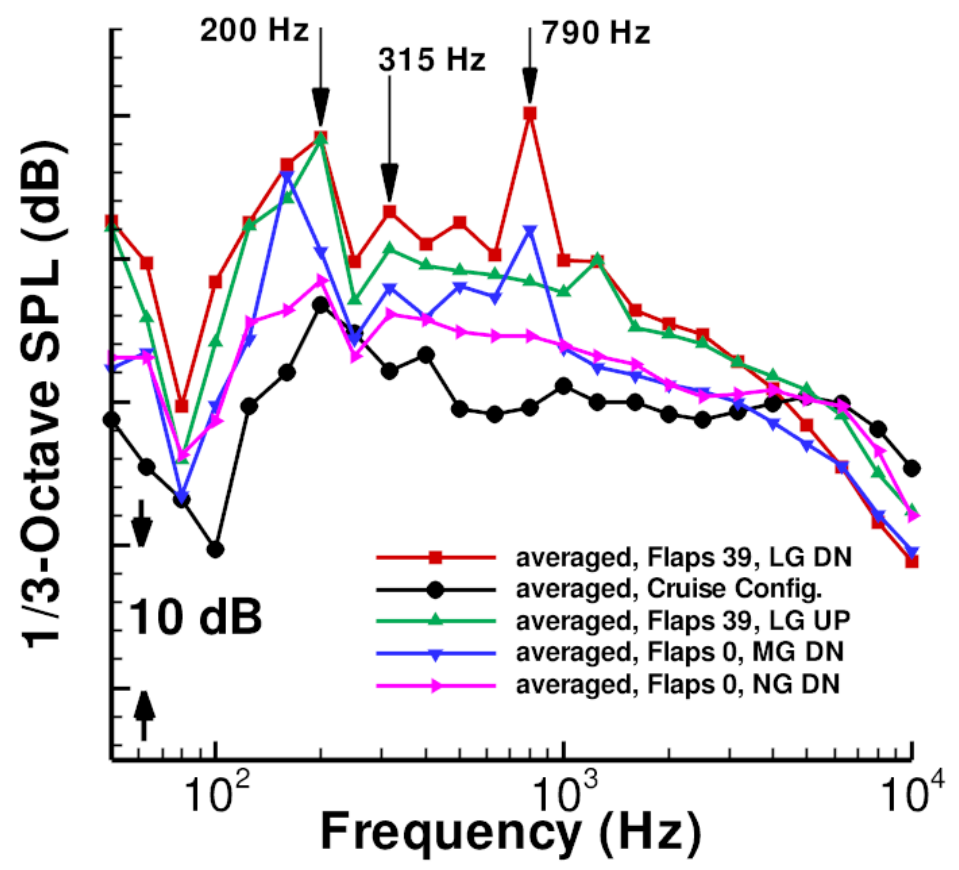

Fig. 14. Comparison of sound levels at 147 knots for five primary configurations 


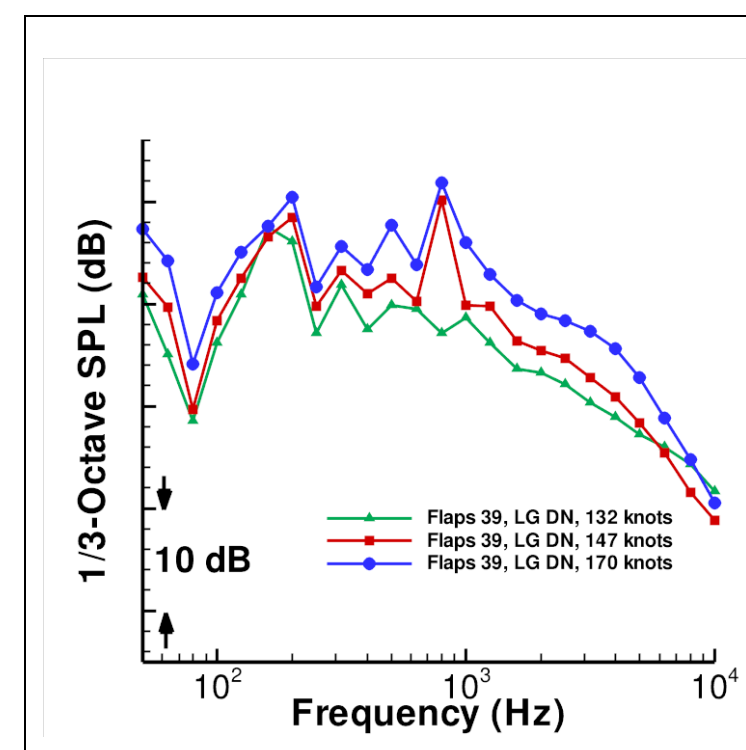

a) unnormalized

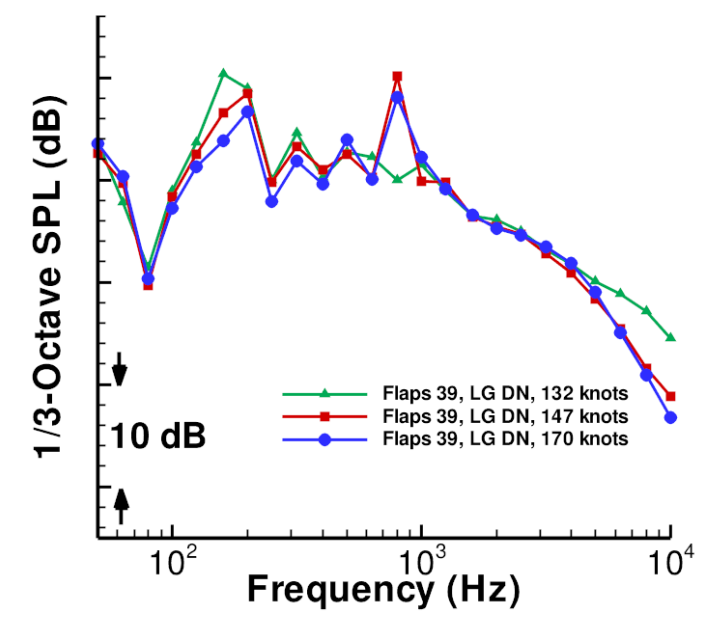

b) normalized by $\mathrm{U}^{6}$

Fig. 15. Noise levels for flaps 39, landing gear down (landing) configuration at different speeds.

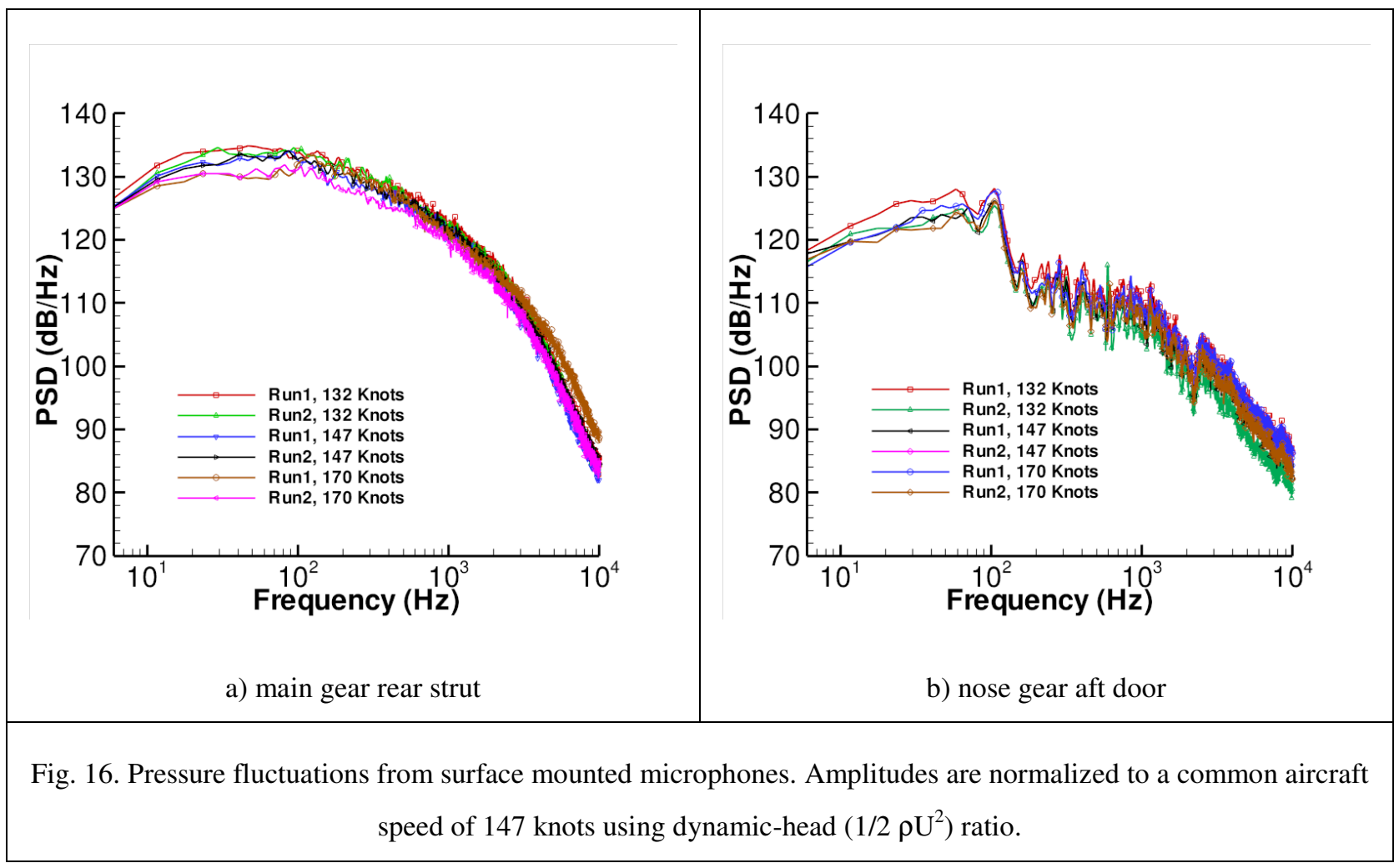

